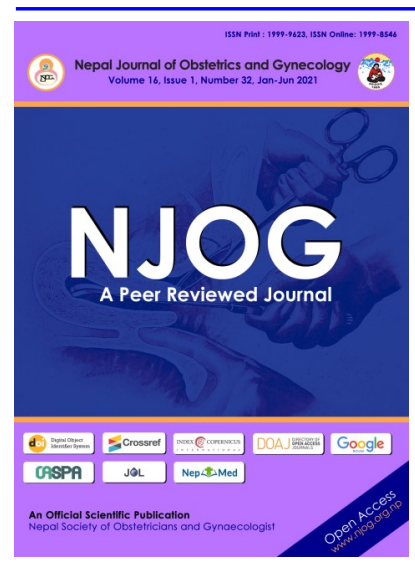

CORRESPONDENCE

Dr. Snigdha Rai

Paropakar Maternity and Women's Hospital, Thapathali, Kathmandu, Nepal

Email:

snigdharaj@hotmail.com; Phone: +977-9851195477

Received: April15, 2021

Accepted: May1, 2021

\section{Citation:}

Rai S. Quality of life and sexual dysfunction in cervical cancer survivors. Nep J Obstet Gynecol. 2021;16 (32):92-96. DOI: https:// doi.org/10.3126/ njog.v16i1.37616

\title{
Quality of life and sexual dysfunction in cervical cancer survivors
}

\author{
Snigdha Rai
}

Paropakar Maternity and Women's Hospital, Kathmandu, Nepal

\section{ABSTRACT}

Aim: To evaluate the quality of life and sexual dysfunction in cervical cancer survivors.

Methods: This is a cross sectional study conducted in Bhaktapur Cancer Hospital from $14^{\text {th }}$ January to $13^{\text {th }}$ April 2021 . Total 136 patients treated for cervical cancer without other coexisting cancers and psychological disorders were interviewed. Independent $t$ test was used to compare means in two categories while ANOVA to compare mean in more than two categories like treatment.

Result: Out of 136 cervical cancer survivors $80 \%$ were from hilly region, $75 \%$ were diagnosed in late stage of disease and average age was 50 years. Total mean FACT-Cx score was $61.1 \pm 14.8$, with lowest score in physical wellbeing $(8.4 \pm 5.5)$ and highest in social and family wellbeing (18.5 \pm 6.2$)$; and $94.8 \%$ of the patients had sexual dysfunction.

Conclusion: This study indicated that the quality of life and sexual function were very low among cervical cancer survivors. Need of counseling regarding the general health and sexual health among cervical cancer is observed.

Keywords: cervical cancer, quality of life, sexual function

\section{INTRODUCTION}

According to World Health Organization (WHO), cervical cancer is the fourth most common cancer in women. In 2018, an estimated 570,000 women were diagnosed with cervical cancer worldwide and about 311,000 women died from the disease. ${ }^{1} \mathrm{~A}$ crude incidence rate of cervical cancer in Nepal is 24.2 per 100,000 women per year with 3504 new cases diagnosed every year and 1872 deaths. $^{2}$

Cervical cancer being a leading gynecological cancer in Nepal, has a profound impact on the quality of life and sexual function of the patients. With increasing survival in patients with carcinoma cervix with various modalities of treatment, the quality of life especially post treatment sexual function has also improved with better technology for radiation therapy and thus there is a great need for wide understanding to address this issue more efficiently.

This study is aimed to evaluate the quality of life and sexual dysfunction among cervical cancer survivors and to determine its relation to various clinic-demographic profiles, stage of the disease and treatment modalities.

\section{METHODS}

It is a cross sectional study done for 3 months from $14^{\text {th }}$ January to $13^{\text {th }}$ April 2021at Bhaktapur cancer Hospitals, Nepal. All women treated for cervical cancer in Bhaktapur cancer hospital during the study period were included in the study. The patients with history of psychiatric disorders, mental and neurological illness, patients in palliative care and those with other coexisting cancer were excluded. Approval from IRB and hospital authority were taken prior to the study.

The research tools like health related quality of life FACT-Cx (Functional Assessment of Cancer Therapy - Cervix) and FSFI (Female Sexual Function Index) were translated in basic Nepali language that could be understood by all Nepalese population which was reviewed and corrected by the experts before introducing it to the targeted patients of cervical cancer.

Demographic variables like name, parity, educational level, occupation and menopausal status were obtained from patients; and information on stage of 
disease, type of cervical cancer, time since diagnosis of disease in years, time since treatment of disease in years and treatment received were taken from the patient's record file. The patients were interviewed based on a specific questionnaire of FACT-Cx and FSFI for scoring. The collected data were then entered in SPSS 20. Independent $t$ test was used to compare means in two categories while ANOVA to compare mean in more than two categories like treatment.

\section{RESULTS}

During the study period, total 142 patients of cervical cancer visited the hospital, out of which 6 patients were excluded ( 2 due to co-existing lung cancer along and 4 due to history of depression). The average age of the patients was 50 years (range $=32$ $70) ; 26(19>1 \%)$ were living together; $48.5 \%$ $(\mathrm{N}=66)$ were menopausal. Majority were from hilly region $(\mathrm{N}=91 ; 66.9 \%)$; living with their partner $(\mathrm{N}=110 ; 80.9 \%)$; smoker $(51.5 \%)$; illiterate $(\mathrm{N}=84$; $61.8 \%)$ and housewife $(\mathrm{N}=103 ; 75.7 \%)$; and $51.5 \%$ $(\mathrm{N}=70)$ were smoker. Most of them $(75 \%)$ who had received treatment for cervical cancer were at least in stage 2 and have undergone concurrent chemoradiation $(63.2 \%)$. [Table-1]
Table-1: Stage of cancer and treatment received

\begin{tabular}{|c|c|c|c|}
\hline \multicolumn{2}{|r|}{ Parameters } & $\mathrm{N}$ & $\%$ \\
\hline \multirow{2}{*}{ 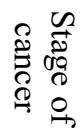 } & $<$ Stage II & 34 & 25 \\
\hline & $\geq$ stage II & 102 & 75 \\
\hline \multirow{4}{*}{ 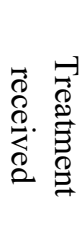 } & Surgery & 24 & 17.6 \\
\hline & Radiotherapy & 12 & 8.8 \\
\hline & Surgery + Radiotherapy & 14 & 10.3 \\
\hline & Concurrent chemoradiation & 86 & 63.2 \\
\hline
\end{tabular}

The lowest mean of the HRQoL domain were noted in physical wellbeing (8.4 \pm 5.5$)$ and emotional wellbeing $(8.4 \pm 3.7)$, while the highest mean were noted in social and family wellbeing ( $18.5 \pm 6.2$ ). The highest interquartile range (IQR) i.e 9.8 was noted in the domain functional wellbeing while the lowest in emotional wellbeing i.e 6. [Table-2]

Total FSFI mean of the patients was 8.1 with SD of 9 and interquartile range of 12.7. [Table-3]

Table-2: Functional Assessment of Cancer Therapy - Cervix (FACT-Cx)

\begin{tabular}{lccccc}
\hline Components & Minimum & Maximum & Mean \pm SD & Median & IQR \\
\hline Physical wellbeing & 0 & 25 & $8.4 \pm 5.5$ & 7 & 8 \\
Social family wellbeing & 5 & 48 & $18.5 \pm 6.2$ & 17.5 & 9 \\
Emotional wellbeing & 0 & 18 & $8.8 \pm 3.7$ & 8.5 & 6 \\
Functional wellbeing & 1 & 28 & $13.6 \pm 6.4$ & 13 & 9.8 \\
Additional concerns & 0 & 57 & $13.9 \pm 6.4$ & 14 & 7 \\
\hline Total FACT-CX & 0 & 93 & $61.1 \pm 14.8$ & 62 & 17 \\
\hline
\end{tabular}

Table-3: Female Sexual Function index score (FSFIS)

\begin{tabular}{lccccc}
\hline Components & Minimum & Maximum & Mean \pm SD & Median & IQR \\
\hline Desire & 1.2 & 44 & $2.2 \pm 3.7$ & 1.2 & 1.2 \\
Arousal & 0 & 5.7 & $1.0 \pm 1.7$ & 0 & 2.4 \\
Lubrication & 0 & 6 & $1.0 \pm 1.8$ & 0 & 2.2 \\
Orgasm & 0 & 6 & $1.1 \pm 1.9$ & 0 & 2.9 \\
Satisfaction & 0.8 & 6.5 & $2.1 \pm 1.6$ & 1.6 & 2.4 \\
Pain & 0 & 6 & $1.1 \pm 2.0$ & 0 & 2.4 \\
\hline Total FSFI & 2 & 33.9 & $8.1 \pm 9.0$ & 3.6 & 12.7 \\
\hline
\end{tabular}

In the univariate analysis of health related quality of life among the patients of cervical cancer the menopausal status $(\mathrm{p}=0.004)$ and educational levels $(\mathrm{p}=0.004)$ were highly significant. Likewise age $(0.031)$ and marital status $(0.025)$ were also significant. However the score was not statistically significant in relation to the stage of disease and the type of treatment received. [Table-4]
In univariate analysis of female sexual function index, age, menopausal status, educational level, stage of cancer and types of treatment received were highly significant. The patient who received surgery had high mean score in compared to the patients who received other modalities of treatment while the least score was found among the patients who received concurrent chemoradiation $(15.5 \mathrm{Vs}$ $5.8, \mathrm{p}$ value $<0.001)$. [Table-5] 
Table-4: Univariate analysis of health- related quality of life (FACT-Cx)

\begin{tabular}{lllc}
\hline & Variables & Mean \pm SD & p-value \\
\hline \multirow{2}{*}{ Age (years) } & $<50$ years & $63.8 \pm 13.7$ & \multirow{2}{*}{0.031} \\
& $\geq 50$ years & $58.3 \pm 15.4$ & \\
Residence & Terai & $64.8 \pm 13.4$ & \multirow{2}{*}{0.063} \\
& Hills/mountain & $59.6 \pm 15.1$ & \\
Menopause & No & $64.8 \pm 11.9$ & \multirow{2}{*}{0.004} \\
& Yes & $57.6 \pm 16.3$ & \\
Marital status & Living with husband & $62.5 \pm 13.7$ & \multirow{2}{*}{0.025} \\
& Not living with husband & $55.3 \pm 17.8$ & \\
Education level & sprimary & $59.1 \pm 15.0$ & \multirow{2}{*}{0.004} \\
& $>$ primary & $67.7 \pm 11.9$ & \\
Smoker & Yes & $57.7 \pm 18.6$ & \multirow{2}{*}{0.180} \\
\multirow{2}{*}{ Stage of cancer } & No & $62.0 \pm 13.6$ & \\
& <stage II & $61.3 \pm 14.9$ & \multirow{2}{*}{0.947} \\
& $\geq$ stage II & $61.1 \pm 14.8$ & \\
Type of treatment & Surgery & $62.9 \pm 16.2$ & \\
& Radiotherapy & $64.2 \pm 13.3$ & \multirow{2}{*}{0.674} \\
& Surgery + Radiotherapy & $58.1 \pm 23.2$ & \\
& Chemo + Radiotherapy & $60.7 \pm 12.9$ & \\
\hline
\end{tabular}

Table-5: Univariate analysis of Female Sexual Function Index (FSFI)

\begin{tabular}{|c|c|c|c|}
\hline & Variables & Mean \pm SD & $p$-value \\
\hline \multirow{2}{*}{ Age (years) } & $<50$ years & $11.4 \pm 10.3$ & \multirow{2}{*}{$<0.001$} \\
\hline & $\geq 50$ years & $4.6 \pm 5.4$ & \\
\hline \multirow{2}{*}{ Residence } & Terai & $6.6 \pm 8.2$ & \multirow{2}{*}{0.216} \\
\hline & Hills/mountain & $8.7 \pm 9.2$ & \\
\hline \multirow{2}{*}{ Menopause } & No & $10.5 \pm 10.0$ & \multirow{2}{*}{0.002} \\
\hline & Yes & $5.8 \pm 7.2$ & \\
\hline \multirow{2}{*}{ Marital status } & Living with husband & $9.4 \pm 9.5$ & \multirow{2}{*}{0.025} \\
\hline & Not living with husband & $2.5 \pm 1.0$ & \\
\hline \multirow{2}{*}{ Education level } & $\leq$ primary & $6.0 \pm 7.0$ & \multirow{2}{*}{$<0.001$} \\
\hline & $>$ primary & $15.3 \pm 11.0$ & \\
\hline \multirow{2}{*}{ Smoker } & Yes & $5.2 \pm 6.0$ & \multirow{2}{*}{0.059} \\
\hline & No & $8.8 \pm 9.4$ & \\
\hline \multirow{2}{*}{ Stage of cancer } & $<$ stage II & $14.1 \pm 10.5$ & \multirow{2}{*}{$<0.001$} \\
\hline & $\geq$ stage II & $6.1 \pm 7.4$ & \\
\hline \multirow{4}{*}{ Type of treatment } & Surgery & $15.5 \pm 10.5$ & \multirow{4}{*}{$<0.001$} \\
\hline & Radiotherapy & $8.9 \pm 9.5$ & \\
\hline & Surgery + Radiotherapy & $8.5 \pm 10.0$ & \\
\hline & Chemo + Radiotherapy & $5.8 \pm 7.0$ & \\
\hline
\end{tabular}

\section{DISCUSSION}

The mean age of the patients with cervical cancer in this study was $50 \pm 9.6$ which was close to the study by Tsai et al (mean age $54.27 \pm 12.1)^{6}$ with the range from $32-70$ years. In our study, $94.8 \%$ of the patients had sexual dysfunction which is much high in compared to previous study by Zhou et al ${ }^{5}$. Among 136 patients included in this study, 110 patients were living with their partners among which only 36 $(32.7 \%)$ were sexually active during past 30 days. Among 67.27 sexually inactive patients, majority
Among 67.27 sexually inactive patients, majority had lack of interest $(63.5 \%)$ followed by fear of bleeding and recurrence (19.4\%), while few of them were sexually inactive even before the diagnosis of cervical cancer most of which were postmenopausal. During the interview about $96.7 \%$ of the patients were not counseled about the sexual function during and post treatment which could be an important underlying factor behind the significantly high rate of sexual dysfunction among these patients. These results similar to the study done by 
Grion et al ${ }^{11}$ who have reported only $30 \%$ of the patients were sexually active in past 3 months, however this is still higher than other similar studies by Vaz et al ${ }^{12}$ and Kirchheiner et $\mathrm{al}^{13}$ who have reported only $21.5 \%$ and $12 \%$ of the patients were sexually active.

This study also revealed that the sexual function i.e higher FSFI mean score was significantly related to the age of the patients $>50$ years, early stage of the cancer and education. Patients who received surgical management were found to have higher FSFI mean score in compared to other modalities but this factor could have stage of the disease as its confounding factor. Unlike the study by Groin et $\mathrm{al}^{11}$ that found positive association with smoking, it was not statistically significant in ours.

The overall mean score for FACT-Cx was found to be 61.1 which is fairly less in compared to other studies. ${ }^{5,16}$ which could be due to its low sample size in compared to other studies. The patient who received radiotherapy and the patients with financial security via health insurance had a better quality of life in the study by Park et al ${ }^{17}$ and Zhou el al ${ }^{5}$ in contrary to our study which should no significant difference in mean score of quality of life among the patients receiving different modalities of treatment. However, this study showed increased score among the patients who lived with their husband which indirectly relates to the financial security.

\section{CONCLUSIONS}

Quality of life and sexual function was found to be very low among the cervical cancer survivors. Age, education, menopausal status and living with their partner had significant association with quality of life with additional factors like treatment modality affecting the sexual function of the patient. The study also implies the importance of health awareness and the potential need of counseling regarding both sexual and general health both during and after the treatment.

\section{ACKNOWLEDGEMENT}

My sincere acknowledgement to Shristee Prajapti and Kalpana Sujakhu from Bhaktapur Cancer Hospital for assisting in data collection process.

\section{REFERENCES}

1. World Health organization. Cervical cancer. Available from: https://www.who.int/healthtopics/cervical-cancer\#tab=tab_1 . Last accessed september 15, 2020.

2. Gyawali B, Keeling J, van Teijlingen E, Dhakal L, Aro AR. Cervical cancer screening in Nepal: ethical considerations. Medicolegal Bioethics. 2015:51-6. DOI: https://doi.org/10.2147/ MB.S77507
3. Fernandes WC, Kimura M. Health related quality of women with cervical cancer. Rev LatinoAM Enfermagen. 2010;18(3):360-7. DOI: $10.1590 / \mathrm{S} 0104-11692010000300010$

4. Santos LND, Castaneda L, Aguiar SSD, THuler LC, Koifman RJ, Bergmann A. Health related Quality of Life with Cervical cancer. Rev Bras Ginecol Obstet. 2019;41:243-50. DOI: http://orcid.org/0000-0001-8573-342X

5. Zhou W, Yang X, Dai Y, WU Q, He G, Yin G. Survey of cervical cancer survivors regarding quality of life and sexual function. J Can Res Ther.2016;12:938-44.

6. Tsai TY, Chen SY, Tsai MH, Su YL, Ho CM, $\mathrm{Su}$ HF. Prevalence and associated factors of sexual dysfunction in cervical cancer patients. J Sex Med. 2011;8:1789-96. doi: 10.1111/ j.1743-6109.2010.01745.x

7. Carter J, Sonoda Y, Baser RE, Rviv L, Chi DS, Brarat, et al. A 2 year study prospective study assessing the emotional, sexual, quality of life concerns of women undergoing radical trachelectomy versus radical hysterectomy, for treatment of early stage cervical cancer. Gynecol Oncol. 2010;119:358-65. Doi: 10.1016/ j.ygyno.2010.07.016

8. Ferrandina G, Mantegna G, Petrillo M, Puoco G, Venditti L, Terzano S, et al. Quality of life and emotional distress in early stage and locally advanced cervical cancer patients: A prospective, longitudinal study. Gynecol Oncol. 2012;124:389-94. doi: 10.1016/ j.ygyno.2011.09.041. Epub 2011 Oct 27

9. Mao JJ, Armstrong K, Bowman MA, Xie SX, Kadakia R, Farrar JT. Symptom burden among cancer survivors : Impact of age and comorbidities. J AM Board Fam Med. 2007;20: 43443. doi: $10.3122 / \mathrm{jabfm} .2007 .05 .060225$

10. Lind H, Waldenstrom AC, Dunberger G, Abany M, ALevronta E. Johansson KA, et al. Late symptoms in long term gynaecological cancer survivors after radiation therapy: A population based cohort study. Br J Cancer. 2011;105:737 -45. doi: 10.1038/bjc.2011.315

11. Grion RC, Baccaro LF, Vaz AF, Paiva LC, Conde DM, Pinto-Neto AM.. Sexual function and quality of life in women with cervical cancer before radiotherapy: a pilot study. Arch Gynecol Obstet. 2016; 293:879-86. https:// doi.org/10.1007/s00404-015-3874-z

12. Vaz AF, Pinto -Neto AM, Conde DM, CostaPaiva L, MOraisis SS, Pedro AO. Quality of life, menopause and sexual symptoms in gynaecologic cancer survivors: a cohort study. Menopuase. 2011;18(6):662-9. doi: 10.1097/ 
gme.0b013e3181ffde7f.

13.Kirchheiner K, Nout RA, Czajka-Pepl A. Health related quality of life and patient reported symptoms before and during definitive radio (chemo) therapy using image-guided adaptive brachytherapy for locally advanced cervical cancer and early recovery - a mono-institutional prospective study. Gynecol Oncol.2015;136(3):415-23. doi: 10.1016/j.ygyno.2014.10.031

14.Jensen PT, Groenvoid M, Klee MC, Thranov I, Peterson MA, Machin D. Longitudnal study of sexual function and vaginal changed after radiotherapy for cervical cancer. Int J Raddiat Oncol Biol Phys. 2003;56(4):937-49. doi: 10.1016/ s0360-3016(03)00362-6

15. Schover LR, Fife N, Gersheson DM. Sexual dysfunction and treatment for early stage cervical cancer. Cancer.1989;63(1):204-12. doi: 10.1002/1097-0142(19890101)63:1<204::aidcncr2820630133>3.0.co;2-u.
16. Tax C, Steenbergen ME, Zusterzeel PLM, Bekkers RLM, Rovers M. Measuring health related quality of life in cervical cancer patients: a systematic review of the most used questionnaire and their validity. BMC Med Res Methodol. 2017;17:15. doi: 10.1186/s12874-016-0289-x

17.Park SY, Bae DS, Nam JH, Cho CH, Jong ML, $\mathrm{Kim} \mathrm{SH}$, et al. Quality of life and sexual problems in disease free survivors or cervical cancer compared with the general population. Cancer. 2007;110:2716-25. doi: 10.1002/cncr.23094 